\title{
An Improved Mathematical Analysis for Roll Dynamics for Hydro-Pneumatic Suspension
}

\author{
(An Novel Approach for Mathematical Modelling for Interconnected \\ Hydro-Pneumatic Suspension )
}

\author{
Pranav Deshpande \\ Bachelor of Engineering (Mechanical Branch) \\ SavitriBai Phule Pune University \\ Pune, India
}

\author{
Manish Shivhare \\ Scientist 'D' \\ Defence Research and Development Organisation \\ DRDO R\&DE (Engrs), Dighi, Pune, India
}

\section{CONFIGURATION OF SUSPENSION STRUT}

Abstract-This paper deals with the novel improved
approach of mathematical modeling for Roll Dynamics for interconnected Hydro-pneumatic suspension. The passive Hydro-pneumatic suspension with inbuilt accumulator type configuration has been considered. A simplified analytical treatment for a half car Roll Plane model has nonlinear stiffness and damping when subjected to Roll instability. The improved mathematical model developed in the paper signifies the advantage of interconnection for the suspension across the axle track. The work considered here has been identified as the basic ground work for further validation by computational and experimental methods.

Keywords- Roll instability; interconnected suspension Nonlinear Stiffness; Orifice Damping; Cornering; Polytrophic index

\section{INTRODUCTION}

Truck and trailers rollover is a serious highway safety problem and it has dire consequences. Heavy freight trailers vehicles have low rollover limits and are thus prone to rollover accidents. Furthermore, the Roll instability further depends on the Vehicles Payload distribution. Thus, to design a robust suspension system for enhanced roll stability is necessary for safety and stability on road and off-road condition.

An improved Roll Dynamic Analysis has been carried out mathematically to formulate a mathematical model for a half car interconnected Hydro-pnuematic suspension model.

The simplified Moment in case of Cornering in pure Roll has been considered and its effect on Moment Developed in the half car Plane Model has been analyzed by mathematical modeling.

A suspension system usually consists of a spring and a damper. The spring alone would already allow the decoupling of input side and isolated side just by its elastic properties and would compensate accelerations/displacements from the input side. The Hydro-pneumatic Suspension has an unconventional configuration with gas accumulator stiffness and orifice damping.
A. Suspension Configuration and its working

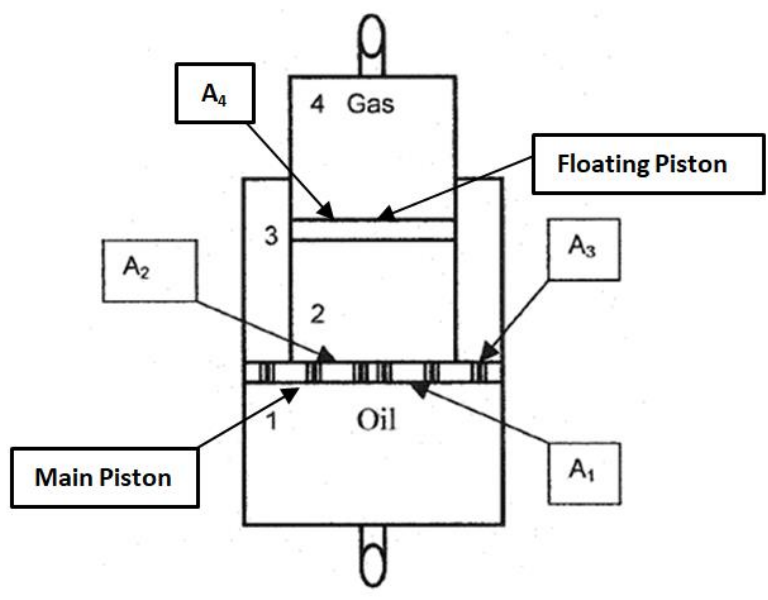

Fig.1

The Hydro-pneumatic Suspension Strut with in-built chamber is schematically as shown above has four chamber as named marked in above fig. Chamber 1,2,3 contains Hydraulic Oil whereas chamber 4 consists of gas (typically nitrogen). The chamber 2 and chamber4 is separated by floating piston. This compact configuration allows a robust construction with optimized working area.

The hydraulic fluid flows through chamber 1 to chamber 2 through orifice. This flow through Hydraulic Restriction leads to damping. The floating piston is employed to separate the gas chambers. The compression of the nitrogen gas in the accumulator is assumed to follow a polytropic process leading to nonlinear, progressively stiffening gas spring characteristics. The damping obtained has nonlinear (quadratic) characteristics as well owing to the flow through orifices. 
III. MATHEMATICAL MODELING

$\mathrm{A}_{2}$

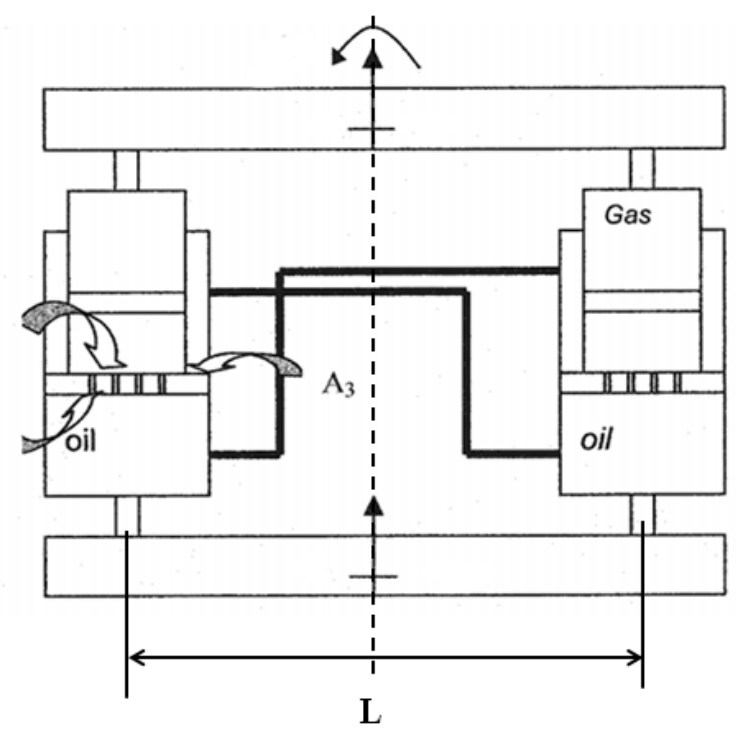

Fig.2

Following are the underlying assumptions considered for mathematical modeling:-

1. The hydraulic fluid (oil) is considered incompressible.

2. The seal friction is negligible.(in working condition reasonable.)

3. The flow through damping orifices is assumed turbulent.

4. The flow through interconnecting pipe is assumed to be laminar.

5. The influence of variation in the temperature due to thermal expansion of fluid and the strut components has been neglected.

6. Mass of floating piston is negligible.

A. Abbreviations and Acronyms

$\rho$ :- Mass density of hydraulic oil

$\mu$ :- Dynamic viscosity of hydraulic oil

$\theta$ :- Angular displacement between strut and horizontal axis.

$\theta$ :- Angular Velocity in Roll Deflection

$\mathrm{u}$ :- Number of orifices

$\varphi$ :- Ratio of Flow Rate between orifice and interconnecting pipe

$\mathrm{n}$ :- Polytropic Index of Gas Compression.

L:- Track Width of Vehicle Plane Model

$\tau$ :- Time response by Roll Deflection

$\mathrm{V}_{\mathrm{p}}$ :- Velocity of hydraulic fluid in Pipe

$\mathrm{A}_{\mathrm{p}}$ :- Area of Pipe

$A_{0}$ :- Area of orifice

$\overline{V_{0}}:-$ Average Velocity of Hydraulic Fluid through Orifice

$x_{\mathrm{pl}}$ :- Displacement of Main Piston of Left Strut

$\dot{x}_{\text {pl }}$ :-Velocity of Main Piston of Left Strut.

$\mathrm{P}_{\mathrm{x}}$ :- Instantaneous Pressure developed in Gas Chamber 4

$V_{\mathrm{x}}$ :- Instantaneous Pressure developed in Gas Chamber 4

$\mathbb{P}_{s}$ :- Static Equilibrium Pressure in gas chamber 4

$V_{g}$ :- Static Equilibrium Pressure in gas chamber 4

$\mathrm{P}_{4 s}$ :- Static Equilibrium Pressure in gas chamber 4.
$V_{4 s}$ :- Static Equilibrium Volume of gas Chamber 4

$A_{11}$ :- Area of Chamber 1 of Left Strut.

$A_{21}$ :- Area of Chamber 2 of Left Strut

$\mathrm{A}_{41}$ :- Area of Chamber 4 of Left Strut.

$F_{\mathrm{RL}:-}$ Force developed by Left strut.

$\mathrm{F}_{\mathrm{RR}}$ :- Force developed by Right strut.

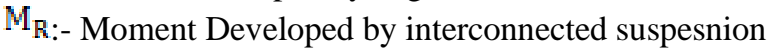

\section{B. Equations}

By Mass Conservation for Chamber 1 in Left Strut:-

Rate of decrease of mass in Chamber 1 left strut = Mass

flow through orifice + Mass flow rate though interconnecting pipe

$$
\rho A_{11} \dot{x}_{p l}=u \rho \overline{V_{0}} A_{0 l}+\rho A_{p} V_{p}
$$

Defining the ratio of flow rate between orifice and interconnecting pipe ${ }^{\mathrm{I}} \varphi^{\mathrm{m}}$ :-

$$
\varphi=\frac{u \rho \overline{V_{0}} A_{0}}{\rho A_{p} V_{p}}
$$

Substituting in Equation (1) we get,

$$
\begin{aligned}
& \rho A_{11} \stackrel{x}{x}_{p l}=(\varphi+1) \rho A_{p} V_{p} \\
& V_{p}=\frac{x}{x_{p l}} \frac{1}{[\varphi+1)} \frac{A_{1 I}}{A_{p}}
\end{aligned}
$$

Thus, by equation (4) the expression of velocity of fluid in pipe as a function of velocity of main piston is obtained.

By Polytropic compression of gas in Gas Chamber

$$
\begin{gathered}
\mathrm{P}_{\mathrm{x}}=\frac{\mathrm{P}_{\mathrm{s}} \mathrm{V}_{\mathrm{s}}^{\mathrm{n}}}{\mathrm{V}_{\mathrm{s}}^{\mathrm{n}}} \quad \Rightarrow \quad \mathrm{P}_{\mathrm{x}} \mathrm{V}_{\mathrm{x}}^{\mathrm{n}}=\frac{\mathrm{P}_{\mathrm{s}} \mathrm{V}_{\mathrm{s}}^{\mathrm{n}}}{\mathrm{V}_{\mathrm{w}}^{\mathrm{n}}} A_{4 s}
\end{gathered}
$$

We have Force developed at any instant of Roll Deflection in either struts.

Moment Developed due forces in Left Strut and right strut due to disturbing Roll Moment/ Deflection (anticlockwise) as shown in the above fig. 2

Force Developed in left strut by gas compression by applying equation (5) for left strut:-

$$
\mathrm{F}_{\mathrm{RL}}=\left\{\frac{\mathrm{P}_{4 s} A_{4 s} \mathrm{~V}_{4 s}^{\mathrm{n}}}{\left(\mathrm{V}_{4 s}-\mathrm{A}_{41} x_{\mathrm{pl}}\right)^{\mathrm{n}}}\right\}
$$

Force Developed in Right Strut (due to flow through interconnecting pipe):-

$$
\mathrm{F}_{\mathrm{RR}}=\rho \mathrm{A}_{\mathrm{p}} \mathrm{V}_{\mathrm{p}}^{2}
$$

Roll Moment developed about the longitudinal axis by the Left and Right about the (in clockwise):- 


$$
\mathrm{M}_{\mathrm{R}}=\left\{\frac{\mathrm{P}_{4 s} \mathrm{~A}_{4 s} \mathrm{~V}_{4 s}^{\mathrm{n}}}{\left(\left(\mathrm{V}_{4 s}-\mathrm{A}_{41} x_{\mathrm{pl}}\right)^{\mathrm{n}}\right.}\right\}\left(\frac{\mathrm{L}}{2}\right)+\rho \mathrm{A}_{p} \mathrm{~V}_{\mathrm{p}}^{2}\left(\frac{\mathrm{L}}{2}\right)
$$

Substituting equation. (2) in equation. (8)

$$
\mathrm{M}_{\mathrm{R}}=\left\{\frac{\mathrm{P}_{4 s} \mathrm{~A}_{4 s} \mathrm{~V}_{4 s}^{\mathrm{n}}}{\left(\mathrm{V}_{4 s}-\mathrm{A}_{41} x_{p 1}\right)^{\mathrm{n}}}\right\}\left(\frac{\mathrm{L}}{2}\right)+\rho \mathrm{A}_{\mathrm{p}}\left(\frac{\mathrm{L}}{2}\right)\left(\frac{1}{(\varphi+1)} \frac{\mathrm{A}_{11}}{\mathrm{~A}_{\mathrm{p}}} \dot{\mathrm{x}}_{\mathrm{pl}}\right)^{2}
$$

$M_{R}=\left\{\frac{P_{4 s} A_{4 s} V_{4 s}^{n}}{\left(V_{4 s}-A_{41} x_{p 1}\right)^{n}}\right\}\left(\frac{L}{2}\right)+\rho A_{p} \frac{1}{(\varphi+1)^{2}}\left(\frac{L}{2}\right)\left(\frac{A_{11} \dot{x}_{p I}}{A_{p}}\right)^{2}$

$\mathrm{M}_{\mathrm{R}}=\left\{\frac{\mathrm{P}_{4 s} \mathrm{~A}_{4 s} \mathrm{~V}_{4 s}^{\mathrm{n}}}{\left(\left(\mathrm{V}_{4 s}-\mathrm{A}_{41} \mathrm{x}_{\mathrm{p} 1}\right)^{\mathrm{n}}\right.}\right\}\left(\frac{\mathrm{L}}{2}\right)+\rho \frac{\mathrm{A}_{11}^{2}}{\mathrm{~A}_{\mathrm{p}}(\varphi+1)^{2}}\left(\frac{\mathrm{L}}{2}\right)\left(\mathrm{x}_{\mathrm{pl}}\right)^{2}$

For Small Roll Deflection:-

$$
\begin{gathered}
x_{p l} \cong \frac{L}{2} \theta ; \quad \dot{x}_{p l}=\frac{\frac{L}{2} \theta}{\tau} \\
\mathrm{M}_{\mathrm{R}}=\left\{\frac{\mathrm{P}_{4 s} \mathrm{~A}_{4 s} \mathrm{~V}_{4 s}^{\mathrm{n}}}{\left(\mathrm{V}_{4 s}-\mathrm{A}_{41} \frac{\mathrm{L}}{2} \theta\right)^{\mathrm{n}}}\right\}\left(\frac{\mathrm{L}}{2}\right)+\rho \frac{\mathrm{A}_{4}^{2}}{(\varphi+1)^{2} \mathrm{~A}_{\mathrm{p}}}\left(\frac{\mathrm{L}}{2}\right)\left(\frac{\mathrm{L} \theta}{\frac{2}{\tau}}\right)_{(12)}^{2} \\
\mathrm{M}_{\mathrm{R}}=\left\{\frac{\mathrm{P}_{4 \mathrm{~s}} \mathrm{~A}_{4 s} \mathrm{~V}_{4 s}^{\mathrm{n}}}{\left(\mathrm{V}_{4 s}-\mathrm{A}_{41} \frac{\mathrm{L}}{2} \theta\right)^{\mathrm{n}}}\right\}\left(\frac{\mathrm{L}}{2}\right)+\rho \frac{\mathrm{A}_{4}^{2}}{(\varphi+1)^{2} \mathrm{~A}_{\mathrm{p}}}\left(\frac{\mathrm{L}}{2}\right)^{\mathrm{a}}(\theta)^{2}
\end{gathered}
$$

Hence, we have obtained a governing Mathematical equation for Roll Moment Developed by disturbing simplified torque on Half Vehicle Model.

\section{Observations}

- From equation (13) it is evident that the Roll Moment developed by the Hydro-pneumatic suspension is a function of roll deflection (by first term) and also roll angular velocity (by second Term)

- The Roll Moment is developed is nonlinear in nature due to Polytropic exponent of gas compression and also quadratic nature of interconnecting pipe flow .

- The enhanced Roll Moment is obtained by the fluid flowing through interconnecting pipe to the other side of track thus improving roll stability of vehicles.

- The Roll Moments is a function of angularSpeed of the roll maneuver owing to interconnection of Hydropneumatic suspension, providing enhanced Roll effect.

- The Above Mathematical Modeling provides the criterion for the dimensioning of Pipe Diameter as it is identified as the crucial parameter for sizing of Diameter for piping.

\section{FUTURE SCOPE}

The above furnished mathematical Model can be perceived as groundwork for computational analysis and experimental analysis can be carried out for the validation of the mathematical Model. Moreover, Bidirectional Spring Configuration of Strut shall provide enhanced Roll Stiffness, thus such configuration can be explored. Mathematical Model for generalized Roll and Body Force can be obtained

\section{ACKNOWLEDGMENT}

I would like to express my heartfelt gratitude to my coauthor and mentor for his constant insightful guidance. I would also like to extend my Thanks to Head of the EMSG Department at DRDO R\&DE (Enrgs.) and Pune University for providing such opportunity to work on this paper.

\section{REFERENCES}

[1] Analysis of Performance of a Hydro-pneumatic Suspension System by Pablo Siqueira Meirelles; Maurício Baldi in 17th International congress of Mechnaical Engineering. Nov. 2003 saopuolo

[2] Hydropneumatic suspensions systems by Wolfgang Bauer

[3] Fundamentals of Vehicle dynamics by Thomas Gillespie

[4] Analysis of hydro-pneumatic intercnnected suspension struts in the rollplane Vehicle Model. By Lewin Wu,2003

[5] An Improved Hydro-Pneumatic Suspension: Mathematical Modeling and Simulation by Tian hong Luo; Ting qiong Cui in International Journal of Research in Mechanical Engineering \& Technology., IJRMET Vol. 5, Issue 1, Novem ber 2014 - Apri 1 2015

[6] Ride and Roll Performance Analysis of Interconnected HydroPneumatic Suspension by Sanjeev Chaudary,April 1998 